\title{
Decomposition and nutrient release temporal pattern of oil palm residues
}

\begin{abstract}
The decomposition and nutrient release temporal patterns of three oil palm residues used as soil mulch were studied. Empty fruit bunches (EFB; $1000 \mathrm{~kg}$ plot-1), Eco-mat (processed EFB carpet; $30 \mathrm{~kg}$ plot -1$)$, and pruned palm fronds (180 kg plot-1) were left to decompose (and sampled monthly) on the soil surface for 8 months. The frond's leaflets had the highest initial concentration for most nutrients, and the frond's rachis and Eco-mat the lowest. The order of residue quality and rate of residue mass loss were: leaflets $>$ fronds $>$ EFB $>$ Ecomat $>$ rachis. EFB however had a higher mass loss rate than the fronds. Residue mass loss and nutrient release rates were faster at the beginning than at the end of the decomposition period. Leaflets released the highest total amount of nutrients (except for $\mathrm{K}$ ), and rachis the lowest. The fronds released either significantly higher (for $\mathrm{N}$ and $\mathrm{Ca}$ ) or not significantly different (for $\mathrm{P}$ and $\mathrm{Mg}$ ) total amount of nutrients than EFB. Converting EFB into Eco-mat had resulted in nutrient losses (e.g. $\mathrm{N}, \mathrm{K}$ and $\mathrm{Mg}$ ) and a residue quality reduction in Eco-mat. This study's results would aid in better soil and oil palm fertilisation management.
\end{abstract}

Keyword: Decomposition; Eco-mat; Empty fruit bunches; Mulch; Oil palm fronds; Oil palm residues; Soil fertility 